\title{
Socio-economic map of Africa
}

\author{
František Mužík \\ Faculty of Civil Engineering, Department of Geomatics, Czech Technical University in Prague, Czech Republic \\ frantisek.muzik@fsv.cvut.cz.
}

Keywords: socio-economic, map, Africa, choropleth map, migration, religion, democracy

\begin{abstract}
:
This map is a poster of an A1 paper size, which describes the current socio-economic situation across the whole African continent throughout years the 2015-2020. The map is a result of a student's work at the Czech technical university in Prague. It focuses on four main sections - economics, the state of democracy, religion and migration crisis. The economic situation of every country is described by proportional symbols that show total export in USD and main sectors of export. Choropleth map as GDP per capita and another choropleth map displaying percentage of people living under the poverty line. The size of the proportional symbols was normalized by a mathematical formula in order to accomplish better visualization and to avoid collisions.
\end{abstract}

The state of democracy is presented by two bar charts displaying the Democracy Index and the Global Freedom Score. The Coxcomb method is used to present the distribution of religion in every country. The states are converted into squares, so it could be referred also as a cartogram.

The migration crisis is described by migration arrows, showing both major roads of migration from Africa to Europe and the Middle East, and migration roads among African countries, however, only the numbers over 1,000 refugees and internally displaced people (IDP) per year are considered. Dot density map refers to the total number of refugees and IDP's living in the given country. The biggest reasons, why so many people are forced to leave their country - armed conflicts - are displayed by the usage of different colors. Disputed areas are shown as areas with dash symbols.

Infographics or explanatory notes are also included in the map, such as the definitions of refugees and IDP's, a list of UNESCO heritage sites in danger and a description of country ISO 3166-1 alpha-3 codes. Other elements of the map are population pyramid of the whole continent and line chart of top investing economies in Africa.

During the map making process, some problems had to be solved. One of the biggest challenges was finding all the data sources and merging them into a poster implementing cartographical and visualization methods. The map needed to be both visually appealing and cartographically correct. It was focused on the usage of every cartographic method only once in order to tell the information in a plenty of different ways.

The main target of this map is to interpret a socio-economic situation in Africa using different methods of cartographic visualization, because maps can describe certain data in a better and more understandable ways than tables. Good examples are migration routes and distribution of religion. All the cartographic work was done in ArcGIS Pro 2.7. Microsoft Excel and GIMP 2.10 were used to finalize the work output. In the beginning, it was planned to create the whole map using only ArcGIS Pro and utilize all the different editing methods that it offers, which was almost successfully done. One of the biggest problems of this approach was the creation of charts. ArcGIS Pro has a very limited options for making charts and in comparison with its other visualization methods, this one is very limited. On the other hand, ArcGIS Pro still provides very wide range of final layout adjustments - comprehensive text editing, advanced symbology styles etc. Although ArcGIS Pro is not perfect and it certainly needs more development in methods of cartographic visualization and map making, it is one of the most sophisticated GIS and mapping software. 